\title{
Ictal quantitative surface electromyography correlates with postictal EEG suppression
}

Anca A. Arbune, MD, * Isa Conradsen, PhD, * Damon P. Cardenas, PhD, * Luke E. Whitmire, PhD, Shannon R. Voyles, BSBE, Peter Wolf, MD, DMsc, Samden Lhatoo, MD, PhD, Philippe Ryvlin, MD, PhD, and Sándor Beniczky, MD, PhD

Neurology ${ }^{\circledR}$ 2020;94:e2567-e2576. doi:10.1212/WNL.0000000000009492
Correspondence

Dr. Beniczky

sbz@filadelfia.dk

\begin{abstract}
\section{Objective}

To test the hypothesis that neurophysiologic biomarkers of muscle activation during convulsive seizures reveal seizure severity and to determine whether automatically computed surface EMG parameters during seizures can predict postictal generalized EEG suppression (PGES), indicating increased risk for sudden unexpected death in epilepsy. Wearable EMG devices have been clinically validated for automated detection of generalized tonic-clonic seizures. Our goal was to use quantitative EMG measurements for seizure characterization and risk assessment.
\end{abstract}

\section{Methods}

Quantitative parameters were computed from surface EMGs recorded during convulsive seizures from deltoid and brachial biceps muscles in patients admitted to long-term video-EEG monitoring. Parameters evaluated were the durations of the seizure phases (tonic, clonic), durations of the clonic bursts and silent periods, and the dynamics of their evolution (slope). We compared them with the duration of the PGES.

\section{Results}

We found significant correlations between quantitative surface EMG parameters and the duration of PGES ( $p<0.001)$. Stepwise multiple regression analysis identified as independent predictors in deltoid muscle the duration of the clonic phase and in biceps muscle the duration of the tonicclonic phases, the average silent period, and the slopes of the silent period and clonic bursts. The surface EMG-based algorithm identified seizures at increased risk (PGES $\geq 20$ seconds) with an accuracy of $85 \%$.

\section{Conclusions}

Ictal quantitative surface EMG parameters correlate with PGES and may identify seizures at high risk.

\section{Classification of evidence}

This study provides Class II evidence that during convulsive seizures, surface EMG parameters are associated with prolonged postictal generalized EEG suppression.

\section{MORE ONLINE}

\section{$\rightarrow$ Class of Evidence \\ Criteria for rating therapeutic and diagnostic studies \\ NPub.org/coe}

\footnotetext{
*These authors contributed equally to this work.

From the Department of Clinical Neurophysiology (A.A.A., P.W., S.B.), Danish Epilepsy Centre, Dianalund, Denmark; Department of Clinical Neurosciences (A.A.A.), "Carol Davila" University of Medicine and Pharmacy, Bucharest, Romania; FORCE Technology (I.C.), Hørsholm, Denmark; Brain Sentinel (D.P.C., L.E.W., S.R.V.), San Antonio, TX; Department of Clinical Medicine (P.W.), Neurological Service, Federal University of Santa Catarina, Florianópolis, SC, Brazil; Center for SUDEP Research (S.L.), National Institute of Neurological Disorders and Stroke, Bethesda, MD; Department of Neurology (S.L.), University of Texas Health Sciences Center at Houston; Department of Clinical Neurosciences (P.R.), CHUV, Lausanne, Switzerland; Department of Clinical Neurophysiology (S.B.), Aarhus University Hospital; and Department of Clinical Medicine (S.B.), Aarhus University, Denmark.

Go to Neurology.org/N for full disclosures. Funding information and disclosures deemed relevant by the authors, if any, are provided at the end of the article. 


\section{Glossary}

$\mathbf{C I}=$ confidence interval; $\mathbf{C S}=$ convulsive seizure; $\mathbf{G T C S}=$ generalized tonic-clonic seizures including focal-to-bilateral tonicclonic seizures; HF = high-frequency; LF = low-frequency; OR = odds ratio; PGES = postictal generalized EEG suppression; qEMG = quantitative EMG; SUDEP = sudden unexpected death in epilepsy; ZC = zero-baseline crossing.

Sudden unexpected death in epilepsy (SUDEP) affects an alarming proportion of patients with epilepsy, with an estimated incidence of 1.2 per 1,000 patient-years. ${ }^{1}$ SUDEP accounts for up to $5.2 \%$ of all deaths in epilepsy. ${ }^{2}$ The major risk factor for SUDEP is the occurrence of generalized tonic-clonic seizures (GTCS). The risk of SUDEP increases in direct proportion to the increase in the number of GTCS, especially in patients with nocturnal seizures who are not closely supervised. ${ }^{3}$

Postictal generalized EEG suppression (PGES), postictal apnea, and postictal immobility ${ }^{4-10}$ occur after GTCS in SUDEP. PGES was first described in a study of patients with epilepsy who died during video-EEG monitoring in which the authors observed that after the abrupt end of the ictal EEG pattern, generalized EEG flattening occurred, as well as respiratory distress, followed by cardiac arrest. ${ }^{4,5}$ PGES is difficult to assess visually because multiple types of artifacts obscure the EEG; automated measurement was successful in only small samples. ${ }^{11}$ A recent stereo-EEG study found increased power in gamma frequencies during postictal attenuation periods. ${ }^{12}$ Moreover, a duration of PGES $>20$ seconds in generalized motor seizures was reported to be significantly associated with SUDEP risk, although this remains controversial. ${ }^{4}$ Patients with type 1 GTCS (bilateral and symmetric tonic arm extension), presence of oral tonicity, occurrence during sleep, and long tonic-phase duration have increased risk for prolonged PGES.,10,13,14

Because of the increased risk for SUDEP, there is a need for automated detection of GTCS and for biomarkers for objective characterization of GTCS. These biomarkers could help identify patients at higher risk, enabling better individual risk assessment and selection of patients for clinical studies aiming at SUDEP prevention. ${ }^{15}$

Previous studies on quantitative analysis of surface EMG recordings showed that muscle activation during GTCS was different from physiologic muscle activation: there were a significant increase in the high-frequency (HF) components and a specific evolution in time of the silent periods that interrupted the clonic bursts. ${ }^{15-20}$ Aspects of these neurophysiologic biomarkers are currently used in seizure detection algorithms, implemented in wearable devices with clearances in the $\mathrm{Eu}-$ ropean Union and United States (SeizureLink and SPEAC). Phase 2 and 3 clinical validation studies showed that the wearable EMG devices detected GTCS with a sensitivity of $94 \%$ to $100 \%$ and 0.7 to 1.4 false alarms per day. ${ }^{21,22}$

Besides automatic seizure detection and alarming, wearable devices can potentially provide valuable clinical information by objective characterization and risk assessment of the seizures. In this study, we correlated quantitative EMG (qEMG) parameters of major convulsive seizures (CS) with seizure severity expressed using PGES and with the seizure types.

\section{Methods}

\section{Patients and recordings}

We have analyzed video-EEG recordings, including surface EMGs from deltoid and biceps muscles, from consecutive patients admitted to the Epilepsy Monitoring Unit at the Danish Epilepsy Centre. ${ }^{23}$ Patients who had at least 1 CS during monitoring (defined as bilateral tonic or clonic jerks) that was documented with the video-EEG-EMG recordings were included. Exclusion criterion was age $<1$ year.

\section{Standard protocol approvals, registrations, and patient consents}

The study had been approved by the regional ethics committee, and patients gave their written consent.

Besides the standard EEG electrode array, surface EMG electrodes (silver/silver chloride 9-mm surface electrodes) were placed on the deltoid and brachial biceps muscles on both sides. The active electrodes were placed on the midpoints of the muscle bellies. The reference electrodes were placed on the acromioclavicular joint, just proximal to the insertion of the deltoid muscle and just proximal to the tendon of the biceps muscle. ${ }^{15}$ EMG was sampled with a frequency of $1,024 \mathrm{~Hz}$ with an antialiasing filter of $512 \mathrm{~Hz}$.

\section{qEMG analyses}

EMG signals were analyzed in MATLAB (MathWorks, Inc, Natick, MA). The authors who performed the qEMG analyses were blinded to all other data. Two different analysis methods were applied to the left deltoid and left biceps muscles.

\section{Deltoid EMG analysis}

Detection of GTCS was based on a previously published automated algorithm. ${ }^{24}$ Briefly, the EMG was high-pass filtered at $150 \mathrm{~Hz}$. GTCS were detected if the number of zero-baseline crossings (ZCs) with hysteresis of $\pm 50 \mu \mathrm{V}$ exceeded the threshold of 253 counts per second for 15 consecutive sliding windows of 1 second, with $75 \%$ overlap.

Durations of the phases of the GTCS were automatically calculated with a previously validated method. ${ }^{16}$ Briefly, using wavelet transformation, we calculated the ratio between the HF component $(64-256 \mathrm{~Hz})$ and the low-frequency (LF) 
component $(2-8 \mathrm{~Hz})$. Tonic maintenance phase was determined between the time points at which the HF/LF was $20 \%$ of the peak value, before and after the peak of the HF/LF. In addition, we calculated the number of sliding windows with ZCs above the threshold.

\section{Biceps EMG analysis}

EMG was high-pass filtered at $8 \mathrm{~Hz}$, and a continuous wavelet transform was performed. The output consisted of complex coefficients that expressed the magnitudes for frequencies ranging from 6 to $400 \mathrm{~Hz}$. The magnitudes of the complex coefficients in 2 frequency ranges were summed over time to create 2 new data traces. These ranges consisted of a high bin, 150 to $260 \mathrm{~Hz}$, and a low bin, 6 to $70 \mathrm{~Hz}$. These traces were normalized to their respective maxima for further computations. EMG signals, HF and LF wavelet-transform output traces, and normalized frequency traces were presented in 3-tier plots. Two data scientists experienced in reviewing EMG data evaluated each CS using the 3-tiered plots and classified them as GTCS or non-GTCS. Any differences in opinion were resolved by consensus. The criteria for GTCS were the presence of tonic, HF EMG with subsequent LF EMG, and (clonic) bursts that devolve over time.

The following EMG measures were calculated: tonic maintenance duration, clonic duration, total tonic-clonic duration, average silent period duration, slope of silent period duration, burst duration, and slope of the burst period duration.

Duration of the tonic and clonic phases was automatically computed from the normalized frequency traces. GTCS possessed an initial period of HF that decayed. Subsequently, at the beginning of this decay, the LF trace either was sustained near its maximum or rose to its maximum. Tonic phase started when the traces first rose to a threshold. The crossover in these normalized traces (LF rising above the HF) constituted the change of phases from tonic to clonic. Once the clonic phase fell to match the baseline, the clonic phase was considered ended. When artifacts affected the automation tool, durations were manually calculated from the frequency traces. Therefore, this method was considered semiautomated.

An automated process created in MATLAB determined the durations of the clonic burst and of the silent periods. The slopes of the evolution in time of each metric were determined by plotting the duration of each period (in milliseconds) along the order of the period (burst or silent period number). All slopes were presented with linear models to simplify the equation comparison. The restricting feature of the automated method was that any burst interval (silent period) must have been a minimum of 40 milliseconds and each burst duration must have had a minimum of 30 milliseconds.

\section{Seizure classification and characterization}

Video-EEG recordings were reviewed by 2 authors (P.R. and S.B.) with $>15$ years of experience in long-term video-EEG monitoring; any differences in opinion were resolved by consensus. CS were first classified as GTCS (including focal to bilateral) and non-GTCS. Then, in each group, seizures were further classified into subcategories. GTCS were classified as type 1,2 , or $3 .{ }^{14}$ We considered and noted that a specific upper limb movement was part of the generalized phase of the seizure if its duration was $>3$ seconds because most of the seizures had many brief movements that were difficult to classify due to artifacts, distorted body positioning, and obscuring of the camera by other people in the room. Non-GTCS were classified as bilateral clonic, bilateral asymmetric-asynchronous focal motor, and opercular seizures.

As previously described, ${ }^{14}$ we selected for further analysis the unequivocally classified seizures (GTCS types 1 and 2 and nonGTCS), thus excluding GTCS type 3. We also determined whether the seizure took place during wakefulness or sleep, as well as whether the patients had oral tonicity (vocalization or mouth opening) during the generalized seizure or bilateral phase of the focal to bilateral seizure.

\section{Postictal generalized suppression of EEG}

As reference standard for the severity of GTCS, we used PGES, a putative surrogate marker for the risk of SUDEP.

We determined PGES by visual inspection on the basis of 2 independent assessments. The first was done by the authors who classified the seizures (P.R. and S.B.), and the second assessment was done independently by another author (A.A.A.) blinded to seizure type and patient status. PGES was defined according to previously described criteria ${ }^{4,9,10}$ as a generalized attenuation of EEG activity starting immediately or within the first 30 seconds after an ictal EEG pattern has stopped, with a duration $\geq 1$ second and amplitude $<10 \mu \mathrm{V}$.

We divided the seizures into 2 groups according to PGES duration ( $<20$ and $\geq 20$ seconds) in accordance with previous articles in which the 20-second threshold indicated a higher risk of SUDEP., ${ }^{4,9}$ We also classified the seizures according to the presence or absence of PGES regardless of seizure type.

\section{Statistical analysis}

Sensitivity, specificity, accuracy, positive predictive value, and negative predictive value, including $95 \%$ confidence intervals (CIs), were calculated for the correct identification of GTCS seizures using the 2 EMG-based methods, as detailed above.

Statistical analysis was performed with SPSS version 19 software (SPSS Inc, Chicago, IL). We calculated means and SD for PGES duration and qEMG parameters. We analyzed the correlations between the different variables using the Pearson $r$ for scalar measurements (PGES duration absolute value and duration of qEMG parameters for deltoid and biceps electrodes), as well as the Spearman rho, Fisher exact probability test, odds ratio (OR), and $\chi^{2}$ (when appropriate) for the other types of relationships. We also performed independent $t$ tests for means and Mann-Whitney $U$ tests according to normality of distribution of the EMG parameters. Lastly, we used the stepwise 
multiple regression analysis to identify the independent qEMG measures for prediction of PGES duration (absolute value and categories). We used a level of statistical significance of $<0.05$.

\section{Algorithm development}

We developed an algorithm for identification of severe PGES ( $\geq 20$-second duration) using surface EMG parameters. Using EMG signals from the biceps muscle, we automatically calculated the tonic-phase duration, clonic duration, and total event durations from GTC seizures using previously described methods. ${ }^{25}$ If an event was not classified as a GTCS, the features were not extracted, and each value was filled with zero for subsequent evaluation. The extracted features were further prepared for neural network training by creating input values based on the deviation of each feature from the mean value of a training set. Events that were not classified as GTCS did not have features correctly extracted. Thus, for training and for evaluation of an event for potential PGES, events that were zero filled were automatically classified as not containing long PGES. These events were also separated from the neural network training component by virtue of automatic rejection of having long PGES.

We added 20 more seizures from 20 patients not included into the exploratory phase. The total of 99 seizures were placed in 5 nearly equally sized groups (group 4 was 1 sample less). For training the network, a 4-fold cross-validation was used in which 20 seizures were used in 3 training groups and 1 isolated test group and 19 seizures were used in a fourth training group.

For machine learning, we used a pattern recognition artificial neural network tool from MATLAB 2019a and bayesian regularization backpropagation with 1 hidden layer, applied to the
EMG features in the training groups. ${ }^{26}$ Each network module was computed 500 times (for each training group), and the node/network weighting for the optimal results was collected for each round of training. The optimized training network was applied to the isolated test group to determine its accuracy.

\section{Classification of evidence}

This study was designed to answer the following question: do automatically computed qEMG parameters identify high-risk CS? The study was retrospective and blinded. All seizure recordings, selected according to the criteria described in detail in the Methods section, were analyzed and evaluated. All seizures had diagnostic reference standard inferred from an independent method (PGES).

This study provides Class II evidence that during CS, surface EMG parameters are associated with prolonged PGES.

\section{Data availability}

Individual deidentified EEG-EMG data in European Data format with annotated seizures will be shared, along with the following related documents: demographic data of the patients, seizure types, and PGES values. Unrestricted access to these data will be made available from the day of the online publication of the article until 2030 in a publicly accessible repository (datadryad.org//) (Dryad DOI is doi:10.5061/dryad.14004q5).

\section{Results}

We recorded 79 CS in 42 patients (17 female patients; age 11-62 years, mean 32.14 years, median 30.5 years). Twentythree patients had 1 seizure, 7 patients had 2 seizures, 7 patients

Table 1 Descriptive statistics of qEMG measurements

\begin{tabular}{|c|c|c|c|c|}
\hline qEMG parameters & Minimum & Maximum & Mean & SD \\
\hline Tonic onset duration-deltoid & 0.00 & 56.20 & 13.14 & 14.78 \\
\hline Tonic maintenance duration-deltoid & 0.00 & 45.10 & 11.78 & 9.13 \\
\hline Tonic-phase duration-deltoid & 0.00 & 83.80 & 24.91 & 18.90 \\
\hline Clonic duration-deltoid & 0.00 & 71.60 & 32.79 & 19.39 \\
\hline Total seizure duration-deltoid & 0.00 & 114.00 & 57.70 & 29.82 \\
\hline Time windows with $\mathrm{ZC}$ above threshold-deltoid & 0.00 & 93.00 & 31.87 & 26.50 \\
\hline Tonic maintenance duration-biceps & 0.00 & 36.50 & 12.67 & 7.61 \\
\hline Clonic duration-biceps & 0.00 & 73.00 & 30.38 & 17.70 \\
\hline Tonic-clonic duration-biceps & 0.00 & 78.20 & 43.0454 & 23.43 \\
\hline Average silent period-biceps & 0.00 & 364.36 & 179.10 & 101.36 \\
\hline Silent period slope-biceps & 0.00 & 33.10 & 11.19 & 7.791 \\
\hline Average burst duration-biceps & 0.00 & 309.99 & 143.15 & 77.74 \\
\hline Burst duration slope-biceps & -3.19 & 1.65 & -0.89 & 1.03 \\
\hline
\end{tabular}

Abbreviations: $\mathrm{qEMG}$ = quantitative EMG; $\mathrm{ZC}$ = zero-baseline crossing. 
had 3 seizures, 4 patients had 4 seizures, and 1 patient had 5 seizures. Fifty-nine CS were GTCS, recorded from 30 patients. Twenty-nine GTCS were type 1 (from 16 patients), 17 were type 2 (from 11 patients), and 13 were type 3 (from 11 patients). Twenty CS were non-GTCS ( 8 bilateral clonic, 9 bilateral asymmetric-asynchronous focal motor, and 3 opercular seizures) from 13 patients. Seizures occurred in $60.8 \%$ ( 48 of 79) of cases during sleep, and $64.6 \%$ (51 of 79 ) had oral tonicity.

The automated algorithm based on ZCs (deltoid muscle) detected GTCS with a sensitivity of $84.75 \%$ (95\% CI 73.01\%-92.78\%), specificity of $90.00 \%$ (95\% CI 68.30\%-98.77\%), and overall accuracy of $86.08 \%$ (95\% CI 76.45\%-92.84\%). Quantitative EMG measurements from the biceps muscle identified GTCS with a sensitivity of $96.61 \%$ (95\% CI $88.29 \%-99.59 \%)$, specificity of $90.00 \%$ (95\% CI 68.30\%-98.77\%), and overall accuracy of 94.94\% (95\% CI 87.54\%-98.60\%).

The qEMG parameters are summarized in table 1 . These included durations of the various seizure phases and their evolution in time (slope). Figures 1 and 2 show examples of the EMG parameters computed from the deltoid and biceps muscles, respectively.

There was good agreement between the 2 visual assessments of PGES duration: average intraclass correlation measure of 0.738 (95\% CI 0.583-0.836, $p<0.001$ ) and moderate agreement for the categorical evaluation of PGES (presence/absence of PGES: $\mathrm{k}=0.787$; PGES $<20$ or $>20$ seconds: $\mathrm{k}=0.665$ ). We used the average of the 2 visual assessments of PGES for comparison with the EMG parameters and seizure types.

PGES was identified in $73.4 \%$ (58 of 79) of CS. Mean duration of PGES for the subset of CS with identified PGES was $36.88 \pm 19.01$ seconds. Considering the 20-second threshold, $60.8 \%$ (48 of 79) of all CS had a long PGES. Seizures with $\geq 50$-second PGES duration accounted for $11.4 \%$ (9 of 79) of cases.

In contrast to GTCS, non-GTCS had shorter or absent PGES $[r(66)=0.549, p<0.001]$ (supplementary material 1 , available from Dryad, doi:10.5061/dryad.14004q5). The risk of PGES $\geq 20$ seconds was significantly associated with GTCS seizures, regardless of type, compared with non-GTCS seizures (OR 74.42, 95\% CI 9.04-612.87; $p<0.001$ ). The risk of PGES occurrence, regardless of duration, was also significantly associated with GTCS vs non-GTCS seizures (OR 43.2, 95\% CI $10.36-180.21 ; p<0.001)$. Oral tonicity was associated with the presence of PGES $[r(79)=0.273, \rho=0.015]$ (supplementary material 2, available from Dryad).

We found significant correlations between the EMG parameters, types of CS (non-GTCS, type 1 GTC, type 2 GTCS), and PGES for both numerical values (duration of PGES) (figure 3) and categories (PGES $<20$ or $>20$ seconds) (figure 4 ).

Three of the 5 deltoid EMG parameters significantly correlated with PGES duration (absolute value), and 6 of the 7
Figure 1 EMG parameters automatically computed from the deltoid muscle
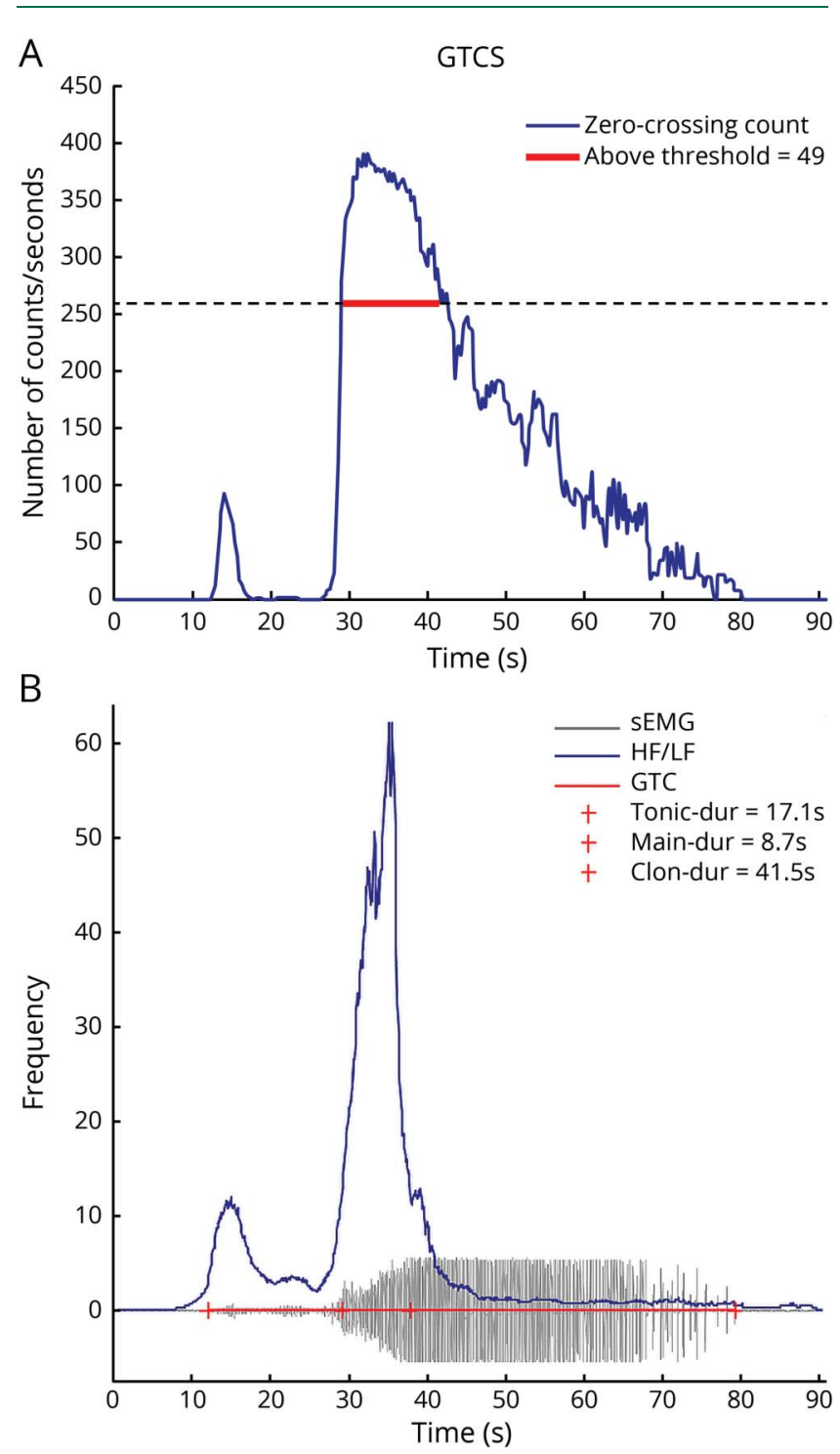

(A) Number of zero-baseline crossings (ZCs) during a generalized tonic-clonic seizures including focal-to-bilateral tonic-clonic seizures (GTCS). Horizontal red line marks the epoch with ZCs above the threshold. (B) Filtered EMG signal during a GTCS (gray), ratio between the high-frequency and low-frequency (HF/ LF) wavelet components (blue), and automatically determined seizure duration (red), segmented (vertical red lines) into phases: tonic onset, tonic maintenance, clonic. sEMG = surface EMG.

biceps EMG parameters statistically significantly correlated ( $p$ $<0.001$ ) with PGES duration (figure 3).

The PGES category duration $>20$ seconds correlated with all EMG parameters except tonic maintenance duration and total tonic duration measured by deltoid EMG (figure 4).

PGES $>50$ seconds correlated with the clonic duration, both deltoid $[r(79)=0.327, \rho=0.003]$ and biceps $[r(79)=0.299, \rho$ $=0.007]$, and total tonic-clonic duration for biceps $[r(79)=$ $0.279, \rho=0.013$. 


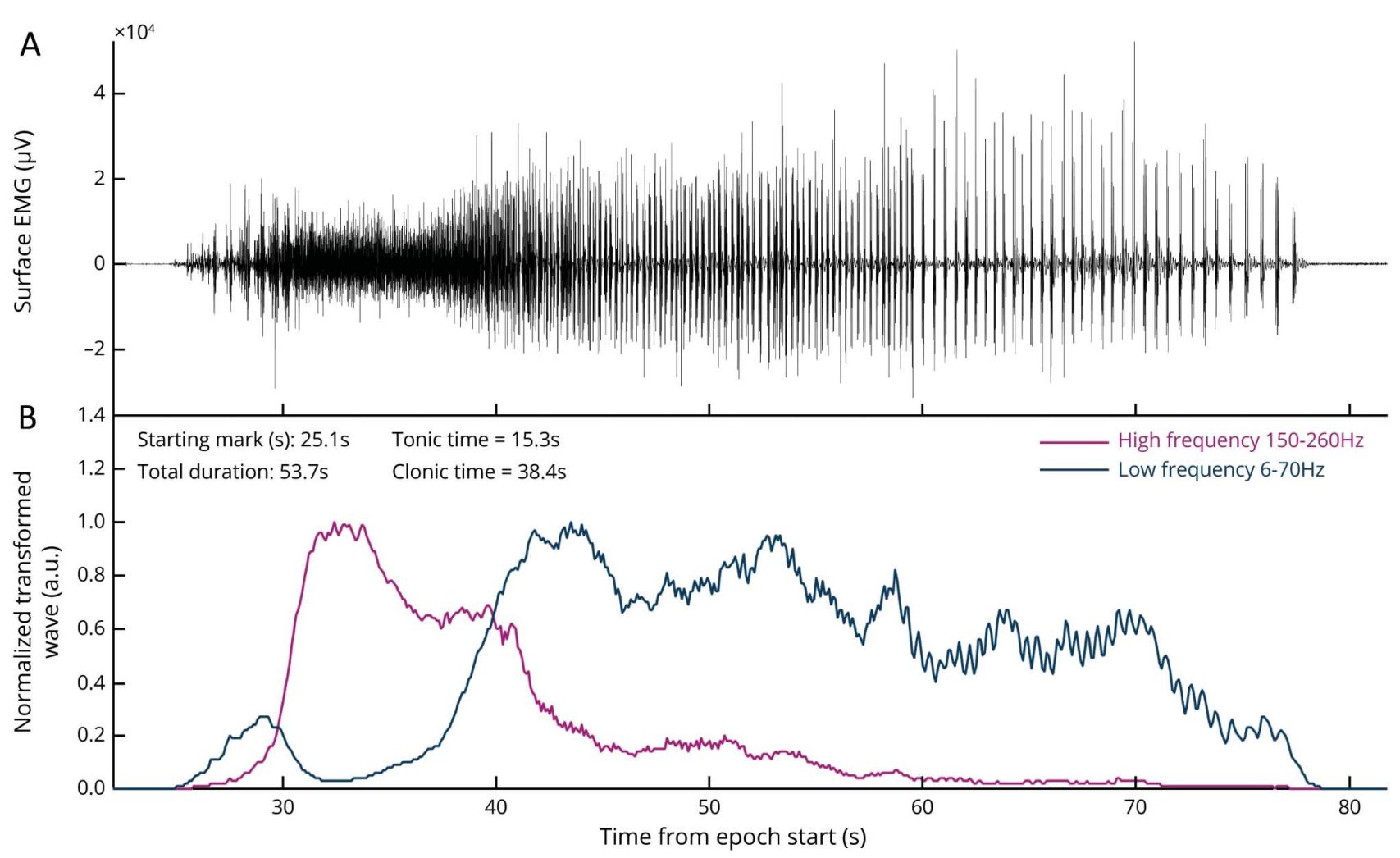

(A) Filtered EMG signal during a generalized tonic-clonic seizure. (B) High-frequency (HF) and low-frequency (LF) components. Normalized HF and LF components.

We also found that the presence of oral tonicity is correlated with a higher duration of the tonic maintenance duration over the deltoid $[r(79)=0.271, \rho=0.033]$, as well as the biceps $[r(79)=0.278, \rho=0.007]$. Oral tonicity was inversely related to the average burst duration measured over the biceps $[r(79)=$ $0.241, \rho=0.032]$. Seizures occurring from sleep seemed to be related to longer clonic-phase durations $[r(79)=0.264, \rho=$ 0.019].

Stepwise multiple regression analysis of the above-mentioned correlations identified the following as independent predictors for PGES duration: clonic duration-deltoid $\left(R^{2}=0.335, p<\right.$ $0.001)$, tonic-clonic duration-biceps $(p<-0.001)$, average silent period duration-biceps $(p=0.005)$, silent period slopebiceps $(p=0.001)$, and burst duration slope-biceps $(p=0.018)$ $\left(R^{2}=0.401, p<001\right)$.

We performed the same analysis for PGES $>20$ seconds and the following were found as independent predictors: clonic duration-deltoid $(p=0.002)$, ZC above threshold-deltoid ( $p=$ $0.002)\left(R^{2}=0.365, p<0.001\right)$, tonic maintenance durationbiceps $(p<-0.001)$, and silent period slope-biceps $(p=0.002)$ $\left(R^{2}=0.395, p<0.001\right)$.

When considering the 50-second threshold, the multiple regression analysis revealed the following as independent contributors: clonic duration-deltoid $\left(R^{2}=0.97, p=0.005\right)$, clonic duration-biceps $(p=0.001)$, and burst duration slope-biceps $(p=0.003)\left(R^{2}=0.174, p=0.001\right)$.

Of all the EMG parameters, clonic duration-deltoid, tonic maintenance duration-biceps, clonic duration-biceps, silent period slope-biceps, and burst duration slope-biceps had normal distributions. We further applied the independentsamples Student $t$ tests to normally distributed qEMG parameters (table 2) and the Mann-Whitney $U$ test for means to the nonnormally distributed qEMG parameters to compare the PGES groups ( $<20$ and $\geq 20$ seconds) (table 3 ). Most demonstrated statistically significant differences between means.

For patients with multiple seizures, we analyzed separately the seizures from the same patients because there was considerable intrapatient variability of the PGES duration (supplementary material 3, available from Dryad, doi:10. 5061/dryad.14004q5), and our goal was to identify individual seizures with long PGES. However, to compensate for potential bias from multiple seizures from the same patients, we recalculated the statistics, using for each patient with multiple seizures the average value from all recorded seizures, and we obtained similar results (supplementary material 4, available from Dryad). 


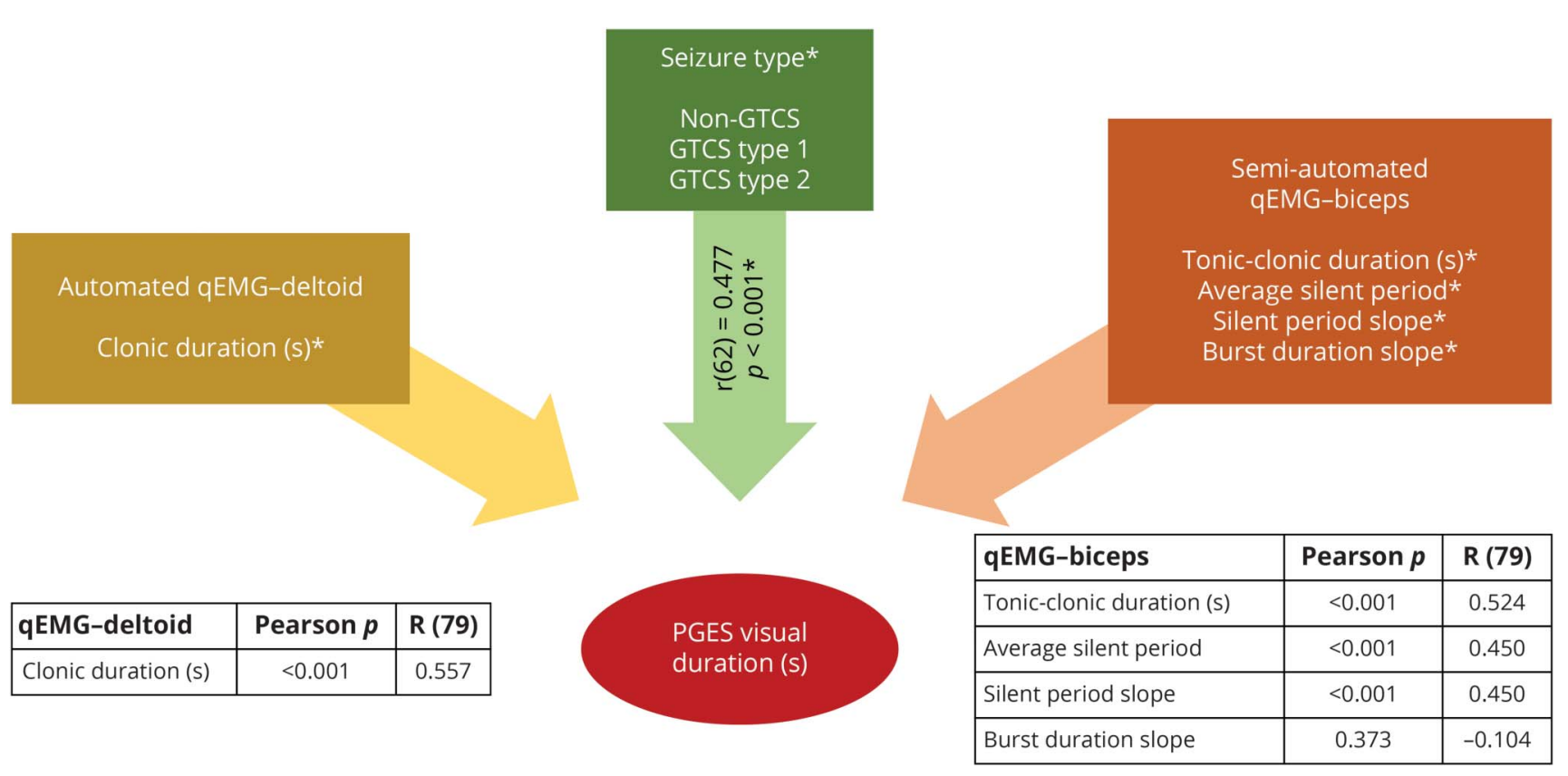

Correlation with quantitative EMG (qEMG) was evaluated with the Pearson $r$ (tables in the figure) and Spearman rho for seizure type (green arrow). GTCS = generalized tonic-clonic seizure including focal-to-bilateral tonic-clonic seizures; PGES = postictal generalized EEG suppression.

In the independent validation dataset, the surface EMG-based algorithm for identification of the most severe GTCS (PGES $\geq 20$ seconds) had a sensitivity of $100 \%$ (95\% CI $71.51 \%-100 \%$ ), specificity of $66.67 \%$ (95\% CI 29.93\%-92.51\%), overall accuracy of $85 \%$ (95\% CI $62.11 \%-96.79 \%)$, and OR of 42.71 (95\% CI 1.9-963).

\section{Discussion}

Quantitative parameters computed from surface EMGs recorded during CS predicted seizure severity, reflected by a putative marker of seizure severity: PGES. Wearable EMG devices using algorithms previously validated for seizure detection could

Figure 4 Correlation of long ( $\geq 20$ seconds) PGES with deltoid and biceps qEMG and seizure type

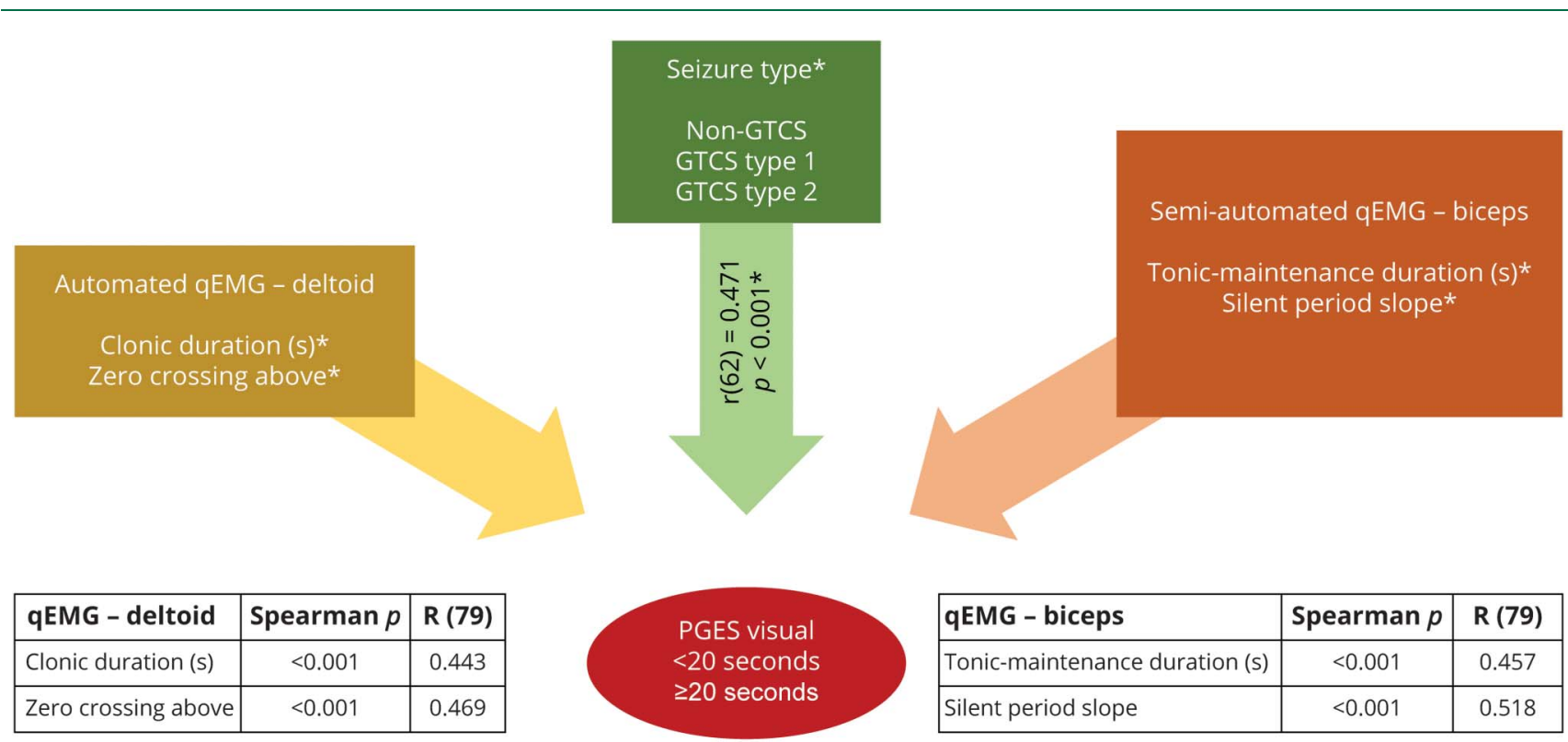

Correlation was evaluated with the Spearman rho (tables in the figure and green arrow). GTCS = generalized tonic-clonic seizure including focal-to-bilateral tonic-clonic seizures; PGES = postictal generalized EEG suppression; qEMG = quantitative EMG. 
Table 2 Independent-samples Student $t$ tests of means for normally distributed qEMG parameters in PGES duration groups

\begin{tabular}{|c|c|c|c|c|c|c|c|}
\hline qEMG parameters & PGES category & No. & Mean & SD & SEM & $t$ Value & $p$ Value \\
\hline \multirow[t]{2}{*}{ Clonic duration-deltoid } & $<20 \mathrm{~s}$ & 31 & 20.21 & 21.08 & 3.79 & -4.90 & $<0.001$ \\
\hline & $\geq 20 \mathrm{~s}$ & 48 & 40.91 & 12.99 & 1.88 & & \\
\hline \multirow[t]{2}{*}{ Tonic maintenance duration-biceps } & $<20 \mathrm{~s}$ & 31 & 7.40 & 7.69 & 1.38 & -5.48 & $<0.001$ \\
\hline & $\geq 20 \mathrm{~s}$ & 48 & 16.07 & 5.32 & 0.77 & & \\
\hline \multirow[t]{2}{*}{ Clonic duration-biceps } & $<20 \mathrm{~s}$ & 31 & 21.26 & 22.22 & 3.99 & -3.50 & 0.001 \\
\hline & $\geq 20 \mathrm{~s}$ & 48 & 36.26 & 10.71 & 1.55 & & \\
\hline \multirow[t]{2}{*}{ Silent period slope-biceps } & $<20 \mathrm{~s}$ & 31 & 6.37 & 6.96 & 1.25 & -5.08 & $<0.001$ \\
\hline & $\geq 20 \mathrm{~s}$ & 48 & 14.30 & 6.67 & 0.96 & & \\
\hline \multirow[t]{2}{*}{ Burst duration slope-biceps } & $<20 \mathrm{~s}$ & 31 & -0.58 & 0.97 & 0.17 & 2.17 & 0.033 \\
\hline & $\geq 20 \mathrm{~s}$ & 48 & -1.08 & 1.03 & 0.15 & & \\
\hline
\end{tabular}

Abbreviations: PGES = postictal generalized EEG suppression; qEMG = quantitative EMG.

provide valuable information about seizure severity. The EMG parameters that had significant correlation with PGES consisted of duration of the tonic-clonic seizures and parameters derived from the seizure phases and from their evolution in time (slope). The algorithm constructed from these EMG parameters identified seizures at increased risk (PGES $\geq 20$ seconds) with an accuracy of $85 \%$ in an independent validation dataset.

With the use of qEMG parameters, GTCS were detected with a sensitivity of $85 \%$ to $97 \%$ and a specificity of $90 \%$. This is similar to the results of the previously published clinical

Table 3 Mann-Whitney $U$ test of means for nonnormally distributed qEMG parameters in PGES duration groups

\begin{tabular}{|c|c|c|c|c|c|c|}
\hline qEMG parameters & PGES category & No. & Mean rank & Sum of ranks & $U$ value & $p$ Value \\
\hline \multirow[t]{2}{*}{ Tonic onset duration-deltoid } & $<20 \mathrm{~s}$ & 31 & 34.74 & $1,077.00$ & 474.00 & 0.007 \\
\hline & $\geq 20 \mathrm{~s}$ & 48 & 43.40 & $2,083.00$ & & \\
\hline \multirow[t]{2}{*}{ Tonic maintenance duration-deltoid } & $<20 \mathrm{~s}$ & 31 & 31.29 & 970.00 & 606.50 & 0.167 \\
\hline & $\geq 20 \mathrm{~s}$ & 48 & 45.63 & $2,190.00$ & & \\
\hline \multirow[t]{2}{*}{ Tonic total duration-deltoid } & $<20 \mathrm{~s}$ & 31 & 35.56 & $1,102.50$ & 581.00 & 0.101 \\
\hline & $\geq 20 \mathrm{~s}$ & 48 & 42.86 & $2,057.50$ & & \\
\hline \multirow[t]{2}{*}{ Total seizure duration-deltoid } & $<20 \mathrm{~s}$ & 31 & 30.03 & 931.00 & 435.00 & 0.002 \\
\hline & $\geq 20 \mathrm{~s}$ & 48 & 46.44 & $2,229.00$ & & \\
\hline \multirow[t]{2}{*}{ Zero crossings above-deltoid } & $<20 \mathrm{~s}$ & 31 & 25.68 & 796.00 & 300.00 & $<0.001$ \\
\hline & $\geq 20 \mathrm{~s}$ & 48 & 49.25 & $2,364.00$ & & \\
\hline \multirow[t]{2}{*}{ Tonic-clonic duration-biceps } & $<20 \mathrm{~s}$ & 31 & 29.02 & 899.50 & 403.50 & 0.001 \\
\hline & $\geq 20 \mathrm{~s}$ & 48 & 47.09 & $2,260.50$ & & \\
\hline \multirow[t]{2}{*}{ Average silent period-biceps } & $<20 \mathrm{~s}$ & 31 & 28.52 & 884.00 & 388.00 & $<0.001$ \\
\hline & $\geq 20 \mathrm{~s}$ & 48 & 47.42 & $2,276.00$ & & \\
\hline \multirow[t]{2}{*}{ Average burst duration-biceps } & $<20 \mathrm{~s}$ & 31 & 27.19 & 843.00 & 347.00 & $<0.001$ \\
\hline & $\geq 20 \mathrm{~s}$ & 48 & 48.27 & $2,317.00$ & & \\
\hline
\end{tabular}

Abbreviations: PGES = postictal generalized EEG suppression; qEMG = quantitative EMG. 
validation studies of seizure detection. ${ }^{21,22}$ However, previous studies addressed only seizure detection, not the assessment of seizure severity.

As reference standard for seizure severity, we used PGES. All patients with SUDEP, documented on video-EEG recordings, had PGES. ${ }^{4,5}$ However, whether PGES is a risk factor of SUDEP remains controversial, and precise measurement of PGES is difficult due to artifacts. ${ }^{10,11}$ To assess the reliability of the reference standard, we determined the intraclass correlation between independent assessments of PGES. This showed good agreement, and we used the average of the 2 assessments as the reference standard in this study. In our series, PGES was present in $73 \%$ of the CS, with a mean duration of $36.88 \pm 19.01$ seconds. This is similar to previous studies from epilepsy monitoring units. ${ }^{13}$ As previously reported, we found that type 1 GTCS (with bilateral and symmetric tonic arm extension) and oral tonicity were correlated with prolonged PGES. ${ }^{9,10,13,14}$

It is still unclear why in some cases GTCS become fatal. One possibility is that the intensity and duration of the seizures have an essential role in initiating a lethal cycle of events. ${ }^{27}$ A previous video-EEG study found that PGES was correlated with the duration of the tonic phase but not with the total seizure duration or the clonic-phase duration. ${ }^{13}$ However, in that study, duration of the seizure phases was determined from video recordings. The transition from tonic to clonic phase is gradual, and determining visually the exact duration of the seizure phases on the basis of video recordings is often arbitrary. Here, we used objective measurements from qEMG parameters, showing that both duration and evolution in time of the seizure phases predict prolonged PGES.

Measurements of electrodermal activity and heart rate variability showed that postictal sympathetic activation and parasympathetic suppression were correlated with PGES. ${ }^{28}$ These postictal changes could contribute to SUDEP. ${ }^{5}$ Predicting the high-risk postictal changes with real-time analysis of EMG signals during seizures can potentially help prevent a fatal outcome.

An important limitation of our study was the use of conventional recording electrodes in epilepsy monitoring units. Ambulatory studies in the patients' home environment and the use of wearable devices are needed to elucidate the clinical potential of monitoring seizure occurrence and seizure severity. However, our study provides quantitative parameters and an algorithm for determining seizure severity, which can be implemented into wearable seizure detection devices.

Long-term ambulatory monitoring of putative surrogate markers of PGES such as the qEMG parameters that we validated in this study will provide important information on the presence of risk factors and objective outcome measures for studies on interventions preventing SUDEP. ${ }^{29}$

\section{Acknowledgment}

The authors thank the staff of the Epilepsy Monitoring Unit, Danish Epilepsy Centre.

\section{Study funding}

The study was supported by a fellowship grant from the International Federation of Clinical Neurophysiology, by a research grant from the Juhl Family Foundation, and by the Swiss National Science Fund/Div3 (320030-179240; SEVERITY).

\section{Disclosure}

A. Arbune and I. Conradsen report no disclosures relevant to the manuscript. D. Cardenas, L. Whitmire, and S. Voyles are employees of Brain Sentinel Inc. P. Wolf, S. Lhatoo, and P. Ryvlin report no disclosures relevant to the manuscript. S. Beniczky reports personal fees from UCB Pharma, Eisai, and Brain Sentinel. Go to Neurology.org/N for full disclosures.

\section{Publication history}

Received by Neurology May 30, 2019. Accepted in final form December 5, 2019.

\begin{tabular}{lll} 
Appendix & Authors & \\
\hline Name & Location & Contribution \\
\hline $\begin{array}{l}\text { Anca A. } \\
\text { Arbune, MD }\end{array}$ & $\begin{array}{l}\text { Danish Epilepsy Centre, } \\
\text { Dianalund, Denmark and } \\
\text { "Carol Davila" University of } \\
\text { Medicine and Pharmacy, } \\
\text { Bucharest, Romania }\end{array}$ & $\begin{array}{l}\text { Designed and } \\
\text { conceptualized study; } \\
\text { analyzed the data; } \\
\text { interpreted the results; } \\
\text { drafted the manuscript }\end{array}$ \\
\hline $\begin{array}{l}\text { Isa } \\
\text { Conradsen, } \\
\text { PhD }\end{array}$ & $\begin{array}{l}\text { FORCE Technology, } \\
\text { Hørsholm, Denmark }\end{array}$ & $\begin{array}{l}\text { Designed and } \\
\text { conceptualized study; } \\
\text { collected and analyzed } \\
\text { the data; interpreted the } \\
\text { results; revised the } \\
\text { manuscript for intellectual } \\
\text { content }\end{array}$ \\
\hline $\begin{array}{l}\text { Damon P. } \\
\text { Cardenas, } \\
\text { PhD }\end{array}$ & $\begin{array}{l}\text { Brain Sentinel, San Antonio, } \\
\text { TX }\end{array}$ & $\begin{array}{l}\text { Analyzed the data; revised } \\
\text { the manuscript for } \\
\text { intellectual content }\end{array}$ \\
\hline $\begin{array}{l}\text { Luke E. } \\
\text { Whitmire, } \\
\text { PhD }\end{array}$ & $\begin{array}{l}\text { Brain Sentinel, San Antonio, } \\
\text { TX }\end{array}$ & $\begin{array}{l}\text { Analyzed the data; revised } \\
\text { the manuscript for } \\
\text { intellectual content }\end{array}$ \\
\hline $\begin{array}{l}\text { Shannon R. } \\
\text { Voyles }\end{array}$ & $\begin{array}{l}\text { Brain Sentinel, San Antonio, } \\
\text { TX, USA }\end{array}$ & $\begin{array}{l}\text { Analyzed the data; revised } \\
\text { the manuscript for } \\
\text { intellectual content }\end{array}$ \\
\hline $\begin{array}{l}\text { Peter Wolf, } \\
\text { MD, DMsc }\end{array}$ & $\begin{array}{l}\text { Federal University of Santa } \\
\text { Catarina, Florianópolis, SC, } \\
\text { Brazil }\end{array}$ & $\begin{array}{l}\text { Designed and } \\
\text { conceptualized study; } \\
\text { revised the manuscript for } \\
\text { intellectual content }\end{array}$ \\
\hline $\begin{array}{l}\text { Matoo, } \\
\text { NhD }\end{array}$ & $\begin{array}{l}\text { Neutional Institute of } \\
\text { Stroke, Bethesda, MD, and } \\
\text { University of Texas Health } \\
\text { Sciences Center at } \\
\text { Houston, Houston, TX, USA }\end{array}$ & $\begin{array}{l}\text { Revised the manuscript for } \\
\text { intellectual content }\end{array}$ \\
\hline
\end{tabular}


Appendix (continued)

\begin{tabular}{|c|c|c|}
\hline Name & Location & Contribution \\
\hline $\begin{array}{l}\text { Philippe } \\
\text { Ryvlin, MD, } \\
\text { PhD }\end{array}$ & $\begin{array}{l}\text { Clinical Neurosciences, } \\
\text { CHUV, Lausanne, } \\
\text { Switzerland }\end{array}$ & $\begin{array}{l}\text { Designed and } \\
\text { conceptualized study; } \\
\text { analyzed the data; } \\
\text { interpreted the results; } \\
\text { revised the manuscript for } \\
\text { intellectual content }\end{array}$ \\
\hline $\begin{array}{l}\text { Sándor } \\
\text { Beniczky, } \\
\text { MD, PhD }\end{array}$ & $\begin{array}{l}\text { Danish Epilepsy Centre, } \\
\text { Dianalund, Aarhus } \\
\text { University Hospital, Aarhus, } \\
\text { and Aarhus University, } \\
\text { Aarhus, Denmark }\end{array}$ & $\begin{array}{l}\text { Designed and } \\
\text { conceptualized study; } \\
\text { analyzed the data; } \\
\text { interpreted the results; } \\
\text { drafted the manuscript }\end{array}$ \\
\hline
\end{tabular}

\section{References}

1. Harden C, Tomson T, Gloss D, et al. Practice guideline summary: sudden unexpected death in epilepsy incidence rates and risk factors: report of the Guideline Development, Dissemination, and Implementation Subcommittee of the American Academy of Neurology and the American Epilepsy Society. Neurology 2017;88:1674-1680.

2. Sveinsson O, Andersson T, Carlsson S, Tomson T. The incidence of SUDEP: a nationwide population-based cohort study. Neurology 2017;89:170-177.

3. Tomson T, Sveinsson O, Carlsson S, Andersson T. Evolution over time of SUDEP incidence: a nationwide population-based cohort study. Epilepsia 2018;59:e120-e124.

4. Lhatoo SD, Faulkner HJ, Dembny K, Trippick K, Johnson C, Bird JM. An electroclinical case-control study of sudden unexpected death in epilepsy. Ann Neurol 2010; 68:787-796.

5. Ryvlin P, Nashef L, Lhatoo SD, et al. Incidence and mechanisms of cardiorespiratory arrests in epilepsy monitoring units (MORTEMUS): a retrospective study. Lancet Neurol 2013;12:966-977.

6. Kuo J, Zhao W, Li CS, Kennedy JD, Seyal M. Postictal immobility and generalized EEG suppression are associated with the severity of respiratory dysfunction. Epilepsia 2016;57:412-417.

7. Peng W, Danison JL, Seyal M. Postictal generalized EEG suppression and respiratory dysfunction following generalized tonic-clonic seizures in sleep and wakefulness. Epilepsia 2017;58:1409-1414.

8. Vilella L, Lacuey N, Hampson JP, et al. Postconvulsive central apnea as a biomarker for sudden unexpected death in epilepsy (SUDEP). Neurology 2019;92:e171-e182.

9. Lamberts RJ, Gaitatzis A, Sander JW, Elger CE, Surges R, Thijs RD. Postictal generalized EEG suppression: an inconsistent finding in people with multiple seizures. Neurology 2013;81:1252-1256.

10. Surges R, Strzelczyk A, Scott CA, Walker MC, Sander JW. Postictal generalized electroencephalographic suppression is associated with generalized seizures. Epilepsy Behav 2011;21:271-274.
11. Theeranaew W, McDonald J, Zonjy B, et al. Automated detection of postictal generalized EEG suppression. IEEE Trans Biomed Eng 2018;65:371-377.

12. Marchi A, Giusiano B, King M, et al. Postictal electroencephalographic (EEG) suppression: a stereo-EEG study of 100 focal to bilateral tonic-clonic seizures. Epilepsia 2019;60:63-73.

13. Tao JX, Yung I, Lee A, Rose S, Jacobsen J, Ebersole JS. Tonic phase of a generalized convulsive seizure is an independent predictor of postictal generalized EEG suppression. Epilepsia 2013;54:858-865.

14. Alexandre V, Mercedes B, Valton L, et al. Risk factors of postictal generalized EEG suppression in generalized convulsive seizures. Neurology 2015;85: 1598-1603.

15. Conradsen I, Wolf P, Sams T, Sorensen HBD, Beniczky S. Patterns of muscle activation during generalized tonic and tonic-clonic epileptic seizures. Epilepsia 2011;52: $2125-2132$

16. Conradsen I, Moldovan M, Jennum P, Wolf P, Farina D, Beniczky S. Dynamics of muscle activation during tonic-clonic seizures. Epilepsy Res 2013;104:84-93.

17. Beniczky S, Conradsen I, Moldovan M, et al. Quantitative analysis of surface electromyography during epileptic and nonepileptic convulsive seizures. Epilepsia 2014 55:1128-1134.

18. Beniczky S, Conradsen I, Moldovan M, et al. Automated differentiation be tween epileptic and nonepileptic convulsive seizures. Ann Neurol 2015;77: 348-351.

19. Beniczky S, Conradsen I, Pressler R, Wolf P. Quantitative analysis of surface electromyography: biomarkers for convulsive seizures. Clin Neurophysiol 2016;127: 2900-2907.

20. Beniczky S, Conradsen I, Wolf P. Detection of convulsive seizures using surface electromyography. Epilepsia 2018;59:23-29.

21. Halford JJ, Sperling MR, Nair DR, et al. Detection of generalized tonic-clonic seizures using surface electromyographic monitoring. Epilepsia 2017;58:1861-1869.

22. Beniczky S, Conradsen I, Henning O, Fabricius M, Wolf P. Automated real-time detection of tonic-clonic seizures using a wearable EMG device. Neurology 2018;90: e428-e434.

23. Craciun L, Alving J, Gardella E, et al. Do patients need to stay in bed all day in the epilepsy monitoring unit? Safety data from a non-restrictive setting. Seizure 2017;49: $13-16$.

24. Conradsen I, Beniczky S, Hoppe K, Wolf P, Sorensen HBD. Automated algorithm for generalized tonic-clonic epileptic seizure onset detection based on sEMG zerocrossing rate. IEEE Trans Biomed Eng 2012;59:579-585.

25. Cardenas DP, Halford JJ, Whitmire LE, et al. Automated processing of single-channe surface electromyography from generalized tonic-clonic seizures to inform semiology. J Clin Neurophysiol 2020;37:56-61.

26. Guo L, Rivero D, Pazos A. Epileptic seizure detection using multiwavelet transform based approximate entropy and artificial neural networks. J Neurosci Methods 2010, 193:156-163.

27. So EL. What is known about the mechanisms underlying SUDEP? Epilepsia 2008 49(suppl 9):93-98.

28. Poh MZ, Loddenkemper T, Reinsberger C, et al. Autonomic changes with seizures correlate with postictal EEG suppression. Neurology 2012;78:1868-1876.

29. Ryvlin P, Ciumas C, Wisniewski I, Beniczky S. Wearable devices for sudden un expected death in epilepsy prevention. Epilepsia 2018;59(suppl 1):61-66. 


\section{Neurology}

Ictal quantitative surface electromyography correlates with postictal EEG suppression Anca A. Arbune, Isa Conradsen, Damon P. Cardenas, et al.

Neurology 2020;94;e2567-e2576 Published Online before print May 12, 2020

DOI 10.1212/WNL.0000000000009492

This information is current as of May 12, 2020

Neurology ${ }^{\circledR}$ is the official journal of the American Academy of Neurology. Published continuously since 1951, it is now a weekly with 48 issues per year. Copyright Copyright $@ 2020$ The Author(s). Published by Wolters Kluwer Health, Inc. on behalf of the American Academy of Neurology.. All rights reserved. Print ISSN: 0028-3878. Online ISSN: 1526-632X.

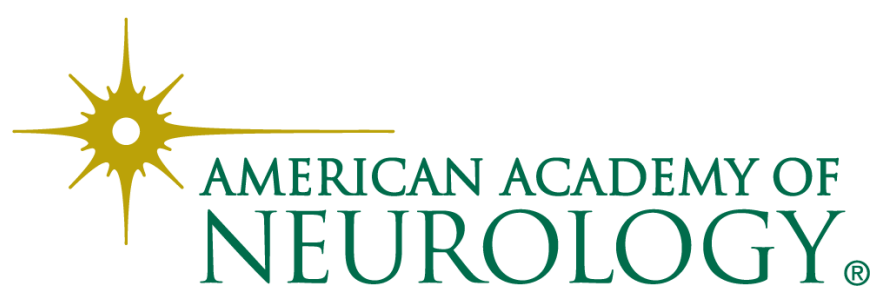




\section{Updated Information \& Services}

References

Citations

Subspecialty Collections

Errata

Permissions \& Licensing

\section{Reprints}

including high resolution figures, can be found at: http://n.neurology.org/content/94/24/e2567.full

This article cites 29 articles, 6 of which you can access for free at: http://n.neurology.org/content/94/24/e2567.full\#ref-list-1

This article has been cited by 1 HighWire-hosted articles: http://n.neurology.org/content/94/24/e2567.full\#\#otherarticles

This article, along with others on similar topics, appears in the following collection(s):

\section{All Epilepsy/Seizures}

http://n.neurology.org/cgi/collection/all_epilepsy_seizures EEG

http://n.neurology.org/cgi/collection/eeg_

\section{EMG}

http://n.neurology.org/cgi/collection/emg

Epilepsy monitoring

http://n.neurology.org/cgi/collection/epilepsy_monitoring_

Generalized seizures

http://n.neurology.org/cgi/collection/generalized_seizures

An erratum has been published regarding this article. Please see next page or:

/content/95/19/890.3.full.pdf

Information about reproducing this article in parts (figures,tables) or in its entirety can be found online at:

http://www.neurology.org/about/about_the_journal\#permissions

Information about ordering reprints can be found online:

http://n.neurology.org/subscribers/advertise

Neurology ${ }^{\circledR}$ is the official journal of the American Academy of Neurology. Published continuously since 1951, it is now a weekly with 48 issues per year. Copyright Copyright ( 2020 The Author(s). Published by Wolters Kluwer Health, Inc. on behalf of the American Academy of Neurology.. All rights reserved. Print ISSN: 0028-3878. Online ISSN: 1526-632X.

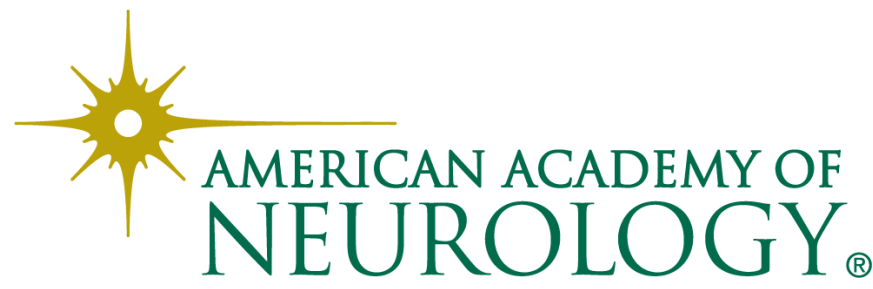




\section{Aerobic exercise improves cognition and cerebrovascular regulation} in older adults

Neurology ${ }^{\circledR}$ 2020;95:890. doi:10.1212/WNL.0000000000010637

In the article "Aerobic exercise improves cognition and cerebrovascular regulation in older adults" by Guadagni et al.," the tests mentioned should read "Card Sorting Test" and "ColorWord Interference Test." The authors regret the errors.

\section{Reference}

1. Guadagni V, Drogos LL, Tyndall AV, et al. Aerobic exercise improves cognition and cerebrovascular regulation in older adults. Neurology 2020;94:e2245-e2257.

\section{Clinical and neural responses to cognitive behavioral therapy for functional tremor}

Neurology ${ }^{\circledR}$ 2020;95:890. doi:10.1212/WNL.0000000000010608

In the article "Clinical and neural responses to cognitive behavioral therapy for functional tremor" by Espay et al., ${ }^{1}$ the final data point in figure 4 for HAM-D correlation should be 0.81 , higher than originally reported. This change does not alter the interpretation of the analysis. The authors regret the error.

\section{Reference}

1. Espay AJ, Ries S, Maloney T, et al. Clinical and neural responses to cognitive behavioral therapy for functional tremor. Neurology 2019; 93:e1787-e1798.

\section{Ictal quantitative surface electromyography correlates with postictal EEG suppression}

Neurology ${ }^{\circledR}$ 2020;95:890. doi:10.1212/WNL.0000000000010638

In the article "Ictal quantitative surface electromyography correlates with postictal EEG suppression" by Arbune et al., ${ }^{1}$ reference 12 should be "Bateman LM, Mendiratta A, Liou JY, et al. Postictal clinical and electroencephalographic activity following intracranially recorded bilateral tonic-clonic seizures. Epilepsia 2019;60:74-84." The authors regret the error.

\section{Reference}

1. Arbune AA, Conradsen I, Cardenas DP, et al. Ictal quantitative surface electromyography correlates with postictal EEG suppression. Neurology 2020;94:e2567-e2576. 